\title{
Rectovaginal fistula after low anterior resection in Chinese patients with colorectal cancer
}

\author{
Hongtu Zheng ${ }^{1,2, *}$, Tianan $\mathrm{Guo}^{2, *}$, Yuchen $\mathbf{W u}^{2}$, Cong $\mathbf{L i}^{1,2}$, Sanjun Cai ${ }^{1,2}$, Fangqi \\ Liu ${ }^{1,2}$ and $\mathrm{Ye} \mathrm{Xu}^{1,2}$ \\ ${ }^{1}$ Department of Colorectal Surgery, Fudan University Shanghai Cancer Center, Shanghai 200032, China \\ ${ }^{2}$ Department of Oncology, Shanghai Medical College, Fudan University, Shanghai 200032, China \\ *These authors contributed equally to this work
}

Correspondence to: Ye Xu, email: xu_shirley021@163.com, xuye021@163.com

Fangqi Liu, email: 12131230023@fudan.edu.cn

Keywords: rectovaginal fistula, low anterior resection

Received: January 26, 2017 Accepted: March 27, $2017 \quad$ Published: April 11, 2017

Copyright: Zheng et al. This is an open-access article distributed under the terms of the Creative Commons Attribution License 3.0 (CC BY 3.0), which permits unrestricted use, distribution, and reproduction in any medium, provided the original author and source are credited.

\section{ABSTRACT}

Rectovaginal fistula is a postoperative complication of low anterior resection. We investigated the incidence of rectovaginal fistula (RVF) after low anterior resection, its risk factors and its optimal treatment. We analyzed data from 1,493 female patients who underwent low anterior resection for colorectal cancer between January 2006 and March 2016. We calculated the incidence of RVF and performed univariate and multivariate logistic regression analyses to identify risk factors. Twenty-four patients experienced RVF, giving an incidence of $1.61 \%$. Univariate analysis revealed a short distance between the tumor and the anal verge $(p<0.001)$, longer surgery duration $(p=0.009)$, unsatisfactory anastomosis $(p<0.001)$, and greater intraoperative blood loss $(p=0.002)$ to be risk factors for RVF. Multivariate analysis showed that only distance between the tumor and the anal verge and unsatisfactory anastomosis were risk factors for RVF. Sixteen patients $(66.7 \%)$ healed within a range of 30-1,225 days (median, 210 days). Twenty-one patients underwent surgery for diverting stoma; of those, 15 of them (71.4\%) recovering after ostomy. These results indicate the primary risk factors for RVF are unsatisfactory anastomosis and short distance between the tumor and the anal verge. Most cases of RVF can be healed using a diverting stoma alone, without the need for additional surgery.

\section{INTRODUCTION}

Rectovaginal fistula (RVF) refers to a pathologic hole formed from the neorectum to the vagina. Clinically, patients may present with feces or gas discharged from the vagina and inflammation in the pelvic cavity, which may lead to severe infection and poor quality of life. Although numerous studies have investigated RVF, very few reports have focused on RVF resulting from low anterior resection (LAR) of colorectal tumors. The incidence of post-LAR RVF reported in the literature is variable, ranging from $0.9 \%$ to $9.9 \%$ [1-7]. Because of limited research in this area and the small number of cases included in previous studies [6], the high-risk factors of post-LAR RVF remain unclear. Therefore, the incidence and risk factors of post-LAR RVF warrant further investigation.
As a postoperative complication of LAR, RVF accounts for only 5\% of all anorectal fistulas [8]. However, once RVF occurs, it's difficult to treat [9]. As RVF has a significant impact on quality of life, physicians should ensure timely treatment to promote a fast recovery for patients with RVF. To date, there is no standard or widely accepted treatment for RVF $[10,11]$. Patients who received surgical treatment are generally considered to have a better prognosis compared with those receiving conservative treatment [12]. However, whether transverse colostomy is superior to ileostomy to repair RVF, whether rectovaginal fistula need to be repaired, and what the optimal time is for stoma closure are still controversial and warrant further investigation.

In this study, we analyzed 24 cases of postoperative RVF out of 1,493 patients with colorectal cancer treated with LAR at Fudan University Shanghai Cancer Center between 
January 2006 and March 2016. We aimed to quantify the incidence and risk factors of post-LAR RVF and to identify optimal treatment methods for patients with post-LAR RVF.

\section{RESULTS}

\section{RVF incidence and time of occurrence}

Among the 1,493 female patients analyzed, 24 were diagnosed with RVF, with an incidence rate of $1.61 \%$. RVF occurred three to 1,161 days post-operation, with a median time of 19.5 days. (Table 1) shows the distribution of cases by time of RVF occurrence. Of note, RVF in our study was never caused by local recurrence of rectal cancer. Out of the 24 patients who underwent RVF treatment, six received neoadjuvant radiotherapy and only two received postoperative adjuvant radiotherapy. The time of RVF occurrence for the latter two patients was 21 days and 27 days after operation (prior to the start of adjuvant radiotherapy in both cases). Other patients in our study who received adjuvant radiotherapy didn't suffer from RVF. Five patients out of the 24 who presented RVF were diagnosed with distant metastases during follow-up, but no VEGF inhibitors were administered prior to RVF occurrence.

\section{High-risk factors}

The results of our analysis of possible RVF high-risk factors are shown in (Table 2). Univariate analysis showed that a short distance between the tumor and the anal verge, long surgery duration, unsatisfactory anastomosis, and heavy blood loss during surgery were significant highrisk factors. Furthermore, the risk factors with statistical significance in multivariate analysis were unsatisfactory anastomosis (HR 6.474, 95\% confidence interval [CI] 2.236-18.743, $p=0.001$ ) and the distance between the tumor and the anal verge (hazard ratio [HR] 0.650, 95\% CI 0.496-0.851, $p=0.002$ ). Results are shown in (Table 3).

\section{Difference between patients who presented RVF within 30 days vs over 30 days after surgery}

(Table 4) compares various characteristics of patients who presented RVF more than 30 days after LAR (20.8\% of all patients) with those of patients who presented RVF within 30 days after LAR and the results are showed in. We found that patients who suffered RVF more than 30 days after LAR had a higher proportion of receiving prophylactic stoma (3/5 vs $2 / 19)$ and neoadjuvant chemoradiation( $4 / 5$ vs $2 / 19)$.

\section{Treatment and prognosis}

\section{Different treatment, follow-up and healing time}

Surgeons may perform prophylactic stoma (colostomy or ileostomy) on patients at high risk of anastomotic leakage(AL) or RVF after LAR in order to divert feces. For patients with RVF, if a prophylactic stoma has been performed during surgery, there is no need for supplemental diversion after RVF occurs. On the other hand, most patients who have not undergone prophylactic stoma will receive supplemental diversion (colostomy or ileostomy). In our study, two patients received prophylactic stoma during the surgery. One case had a small RVF; thus, she opted for fistula suture instead of diverting stoma. The remaining 21 patients $(87.5 \%)$ underwent colostomy or ileostomy as a supplemental diversion (including 18 cases of transverse colostomy alone, one case of transverse colostomy plus RVF suture, and two cases of terminal ileostomy alone). Supplemental diversion and prognosis statistics are presented in (Table 5).

After RVF occurrence, the follow-up time for patients ranged from 228 to 3,733 days (median $=1,774$ days; mean $=1574$ days). By the time we wrote the manuscript, 16 cases had healed, and this the healing rate was $66.7 \%(16 / 24)$. The approximate range of healing time was $30-1,225$ days (median $=210$ days; mean $=330$ days).

Among the 21 patients who underwent therapeutic ostomy (supplemental diverting stoma), one patient who underwent transverse colostomy combined with RVF suture healed well. Another 14 patients also healed after ostomy surgery alone, without RVF suture. Three patients died before stoma closure surgery because of tumor recurrence, so their RVF healing status is unclear. By the time we wrote the manuscript, three patients with RVF had not yet healed. Therefore, the healing rate was at least $71.4 \%(15 / 21)$. Since most RVFs heal after colostomy or ileostomy, patients with RVF who received such surgeries may not need additional surgery such as muscle or tissue transfer flaps. The RVF healing time for the 21 patients who underwent supplemental diversion was ranged from 30 to 1,225 days (median $=222$ days). Apart from the 21 patients, one patient underwent RVF suture alone instead of supplemental diverting stoma, healing one month after suture surgery. The two patients who underwent prophylactic ostomy had not yet undergone stoma closure surgery at the time of writing the manuscript.

Out of the 24 patients who suffered from RVF, six patients underwent neoadjuvant chemoradiation, four of which healed $(67 \%)$ while two of them died before healing. There was no statistical association between the age of patients and the healing time of $\operatorname{RVF}(P=0.928)$. Although our data suggested a correlation between healing time and age (i.e., the older the patient, the longer the time for RVF healing), the results were not statistical significant (Table 6).

\section{Distal colon irrigation}

Some patients received distal colon irrigation during supplementary transverse colostomy. The process of distal colon irrigation was as follows: a large volume of saline was poured from the stoma into distal colon. The anus was dilated at the same time so that any residual feces in the 


\begin{tabular}{lcc}
\hline \multicolumn{1}{c}{$\boldsymbol{n}$ = days after LAR } & Number of patients with RVF & Percentage \\
\hline $1<n \leq 10$ & 7 & $29.2 \%$ \\
$10<n \leq 20$ & 7 & $29.2 \%$ \\
$20<n \leq 30$ & 5 & $20.8 \%$ \\
$n>30^{*}$ & 5 & $20.8 \%$ \\
\hline
\end{tabular}

$\mathrm{LAR}=$ low anterior resection, $\mathrm{RVF}=$ rectovaginal fistula.

*In these 5 patients, RVF occured at 37, 90, 121, 274, and 1161 days after LAR.

distal colon could be washed out. This process continued until the saline discharged from the anus contained no feces.

Among the 19 patients who underwent therapeutic transverse colostomy (including 18 cases of transverse colostomy alone and one case of transverse colostomy plus RVF suture), eight received intraoperative distal colonic irrigation. Our statistical analyses revealed no significant difference in total hospitalization costs, hospitalization duration, or healing time between patients who received distal colonic irrigation and those who did not (Table 7).

\section{Impact on hospitalization days and cost}

The total number of days of hospitalization and postoperative hospitalization, and the total hospitalization cost, were significantly higher for the RVF group compared with the non-RVF group. The total cost of secondary hospitalization due to RVF treatment ranged between $\$ 1,722$ and $\$ 4,148$ USD (median $=\$ 2,384$ USD; Table 8).

\section{DISCUSSION}

In this study, the incidence of post-LAR RVF was $1.61 \%$, while previous publications reported incidence values ranging from 0.9 to $9.9 \%$ (Table 9 ). This difference may be due to inadequate number of cases recruited in previous studies and various inclusion criteria utilized by these studies. According to the literature, most anastomotic leakage(AL) occurs 3.5-8 days after LAR surgery [1315]. In this study, RVF occurred 3-1161 days after surgery (median $=19.5$ days). This indicates that RVF occurs later and over a broader time span compared with AL. The reason for RVF occurring later might be explained by the mechanism underlying the formation of RVF, such as local inflammation and the formation of abscess at the anastomosis site, which gradually causes edema of the vaginal wall, weakening the tissue and leading to eventual rupture and RVF. Another reason for RVF occurrence is stapling the vaginal wall during anastomosis in LAR surgery, which results in necrosis of the vaginal wall and RVF.

High-risk factors for the occurrence of post-LAR RVF are unclear. However, our study here shows that the shorter the distance between the tumor and the anus, the greater the incidence of postoperative RVF. This is similar to previous studies showing that the incidence of colorectal $\mathrm{AL}$ increased in patients with tumors near the anus [16, 17]. The are two possible reasons for the distance between the anus and tumors being a predictor of RVF. First, the lower the location of the rectal tumor, the greater the area of the vaginal wound during rectum-vagina separation in LAR, leading to an increased probability of vaginal injury. Furthermore, lower tumor sites caused anastomosis at lower sites with poorer exposure, thereby increasing the probability of clipping the posterior vaginal wall with the stapler. There is also a greater probability of RVF occurrence in patients with a fragile and edematous bowel wall, poor anastomotic blood supply, obvious tension in the anastomosis site, or the presence of obstructive symptom before surgery. The surgeons will avoid stapling of the vagina at the time of colorectal anastomosis. However, it's difficult for the surgeons to perform stapling of the vagina under poor exposure conditions. Therefore, it is difficult to determine how many cases of RVF were secondary to stapling of the vagina. Surgeons can evaluate the status of the anastomosis site; i.e., they can assess whether there's poor blood supply, obvious tension, fragile tissue, or edema at the anastomosis site, and perform an intraoperative air leak test $[18,19]$; In this study, these factors were considered as unsatisfactory anastomosis. Both univariate and multivariate analyses showed that this factor was predictive of RVF occurrence.

Univariate analysis identified long surgery duration and heavy intraoperative bleeding as high-risk factors for RVF, but multivariate analysis did not identify these as independent factors.

We also investigated whether neoadjuvant radiotherapy increases the risk of RVF. Radiotherapy may lead to vascular injury, chronic inflammation and ischemia, which may lead to RVF formation [20]. Previous studies have reported that neoadjuvant radiotherapy has no influence on the incidence of AL [21]. The results of our study showed that neoadjuvant radiotherapy was not a high-risk factor for RVF.

A variety of methods and materials have been reported for vaginal repair and RVF treatment $[12,24-$ 26]. Early intervention including supplementary diverting stoma can improve the success rate of RVF healing [22]. 


\begin{tabular}{|c|c|c|c|}
\hline & RVF (+) $n=24$ & RVF (-) $n=1469$ & $p$-value \\
\hline \multicolumn{4}{|l|}{ Patient-related } \\
\hline Age (years) & 54.4 & 57.2 & 0.24 \\
\hline Body mass index & 23.7 & 22.9 & 0.18 \\
\hline Hypertension & $5(21 \%)$ & $294(20 \%)$ & 0.89 \\
\hline Diabetes & $1(4 \%)$ & $88(6 \%)$ & 0.66 \\
\hline History of weight loss & $8(35 \%)$ & $617(42 \%)$ & 0.83 \\
\hline \multicolumn{4}{|l|}{ Tumor-related } \\
\hline Distance between tumor and anus* $(\mathrm{cm})$ & 6.00 & 7.98 & $<0.001$ \\
\hline Maximum tumor diameter $(\mathrm{cm})$ & 3.1 & 3.5 & 0.15 \\
\hline T stage & & & 0.95 \\
\hline $\mathrm{Tx}$ & 0 & 40 & \\
\hline T0 benign & 0 & 75 & \\
\hline $\mathrm{T} 1$ & 2 & 136 & \\
\hline $\mathrm{T} 2$ & 9 & 310 & \\
\hline $\mathrm{T} 3$ & 5 & 372 & \\
\hline $\mathrm{T} 4$ & 8 & 536 & \\
\hline $\mathrm{N}$ stage & & & 0.165 \\
\hline No & 16 & 847 & \\
\hline N1 & 7 & 375 & \\
\hline $\mathrm{N} 2$ & 1 & 247 & \\
\hline TNM stage & & & 0.256 \\
\hline Benign or Tis & 2 & 158 & \\
\hline I & 6 & 247 & \\
\hline II & 8 & 347 & \\
\hline III & 8 & 605 & \\
\hline IV & 0 & 112 & \\
\hline Lymph node dissected (mean) & 14.1 & 13.9 & 0.871 \\
\hline Lymph node metastasis (mean) & 1.04 & 1.72 & 0.350 \\
\hline \multicolumn{4}{|l|}{ Treatment-related } \\
\hline Neoadjuvant radiotherapy & $6(25 \%)$ & $176(12 \%)$ & 0.10 \\
\hline Surgery duration (minutes) & 137.6 & 114.3 & 0.009 \\
\hline Laparoscopic surgery & $2(8 \%)$ & $176(12 \%)$ & 0.63 \\
\hline Prophylactic ostomy & $5(21 \%)$ & $147(10 \%)$ & 0.11 \\
\hline Unsatisfactory anastomosis & $6(25 \%)$ & $59(4 \%)$ & $<0.001$ \\
\hline Intraoperative blood loss (ml) & 115.0 & 64.4 & 0.002 \\
\hline Major combined organ resection & $2(8 \%)$ & $59(4 \%)$ & 0.34 \\
\hline Combined resection of vaginal wall & $1(4 \%)$ & $31(2.1 \%)$ & 0.499 \\
\hline Combined resection of uterus and ovary & & & 0.390 \\
\hline None & $22(91.6 \%)$ & $1398(95.2 \%)$ & \\
\hline Hysterectomy & 0 & $1(0.1 \%)$ & \\
\hline Oophorectomy & $1(4.2 \%)$ & $39(2.7 \%)$ & \\
\hline Hysterectomy+unilateral oophorectomy & 0 & $5(0.3 \%)$ & \\
\hline Hysterectomy+bilateral oophorectomy & $1(4.2 \%)$ & $26(1.8 \%)$ & \\
\hline
\end{tabular}

*Distance between tumor and anus refers to distance from the lower tumor margin to the anus based on the results of digital anal examination and intraoperative measurement. 
Table 3: Multivariate logistic regression analysis of high-risk factors

\begin{tabular}{lccc}
\hline & $\boldsymbol{p}$-value & Hazard Ratio & $\mathbf{9 5 \% ~ C I ~}$ \\
\hline Distance between tumor and anus & 0.002 & 0.650 & $0.496-0.851$ \\
Surgery duration & 0.19 & 1.006 & $0.997-1.014$ \\
Unsatisfactory anastomosis & 0.001 & 6.474 & $2.236-18.743$ \\
Intraoperative blood loss & 0.20 & 1.003 & $0.999-1.007$ \\
\hline
\end{tabular}

Table 4: Difference between patients who developed RVF within 30 days vs over 30 days after surgery

\begin{tabular}{|c|c|c|c|}
\hline & $\begin{array}{c}\mathrm{RVF}(\leq 30 \text { days }) \\
n=19\end{array}$ & $\begin{array}{c}\text { RVF (>30 days) } \\
n=5\end{array}$ & $P$ value (Univariate analysis) \\
\hline \multicolumn{4}{|l|}{ Patient-related } \\
\hline Age (years) & 54.6 & 53.6 & 0.896 \\
\hline Body mass index & 24.4 & 21.1 & 0.144 \\
\hline Hypertension & $3(16 \%)$ & $2(40 \%)$ & 0.254 \\
\hline Diabetes & $1(5 \%)$ & 0 & 0.619 \\
\hline \multicolumn{4}{|l|}{ Tumor-related } \\
\hline Distance between tumor and anus $(\mathrm{cm})$ & 5.87 & 6.50 & 0.336 \\
\hline Maximum tumor diameter $(\mathrm{cm})$ & 3.96 & 4.70 & 0.349 \\
\hline T stage & & & 0.79 (Chi-square test) \\
\hline $\mathrm{Tx}$ & 0 & 0 & \\
\hline T0 benign & 2 & 0 & \\
\hline $\mathrm{T} 1$ & 6 & 1 & \\
\hline $\mathrm{T} 2$ & 5 & 2 & \\
\hline $\mathrm{T} 3$ & 6 & 2 & \\
\hline $\mathrm{T} 4$ & 0 & 0 & \\
\hline \multicolumn{4}{|l|}{ Treatment-related } \\
\hline Neoadjuvant radiotherapy & $2(11 \%)$ & $4(80 \%)$ & 0.001 \\
\hline Surgery duration (minutes) & 132.6 & 156.4 & 0.234 \\
\hline Laparoscopic surgery & $2(11 \%)$ & 0 & 0.471 \\
\hline Prophylactic ostomy & $2(11 \%)$ & $3(60 \%)$ & 0.114 \\
\hline Unsatisfactory anastomosis & $4(21 \%)$ & $2(40 \%)$ & 0.406 \\
\hline Intraoperative blood loss (ml) & 128.8 & 68.0 & 0.564 \\
\hline Major combined organ resection & $2(19 \%)$ & 0 & 0.471 \\
\hline
\end{tabular}

Diverting stoma can also reduce the pressure gradient between the rectum and the vagina [23], which helps fistula heal after repair surgery. Out of the 24 patients who suffered from RVF in our study, 21 patients underwent colostomy or ileostomy as a supplemental diversion after RVF occurrence (including one case receiving RVF suture at the time of colostomy). The patients who underwent supplemental diversion didn't receive fistula-repair surgery (i.e., muscle or tissue transfer flaps). 16 patients were confirmed to have healed from RVF during follow up. Thus, we found that most cases of RVF can heal after colostomy or ileostomy. Therefore, patients with RVF may not need additional surgery such as muscle or tissue transfer flaps.

Distal irrigating during surgery in patients undergoing transverse colostomy or ileostomy can theoretically promote early fistula healing or shorten hospitalization time. However, we found no significant difference between the irrigation and non-irrigation groups in our study in terms of total hospitalization cost and time.

The role of prophylactic stoma in the prevention of postoperative RVF is unclear. In a clinical trial involving 
Table 5: Supplemental diversion and prognosis statistics

\begin{tabular}{|c|c|c|c|}
\hline Treatment method & & $\begin{array}{l}\text { Number of } \\
\text { cases }\end{array}$ & Outcome description \\
\hline \multirow[t]{3}{*}{ Therapeutic ostomy } & Transverse colostomy & 18 & $\begin{array}{l}\text { Healed after ostomy }(n=14) \text {. } \\
\text { Died before stoma closure due to } \\
\text { tumor recurrence }(n=3) \text {. } \\
\text { Not healed to date }(n=1) \text {. }\end{array}$ \\
\hline & Transverse colostomy + RVF suture & 1 & Healed well \\
\hline & terminal ileostomy & 2 & Not healed to date \\
\hline Prophylactic ostomy & $\begin{array}{l}\text { transverse colostomy or } \\
\text { end ileostomy }\end{array}$ & 2 & $\begin{array}{l}\text { Have not undergone stoma closure } \\
\text { surgery to date }\end{array}$ \\
\hline $\begin{array}{l}\text { RVF suture without } \\
\text { diverting stoma }\end{array}$ & & 1 & Healed 1 month after surgery \\
\hline
\end{tabular}

Table 6: Comparison of healing time of RVF patients with different age

\begin{tabular}{lcccc}
\hline & Mean healing time with different age & \multicolumn{2}{c}{ Comparison of mean healing time with different age } \\
\hline & Age & healing time (range) & healing time & $P$ value \\
\hline$<45$ & $231(189 \sim 269)$ & $<45$ vs $\geq 45$ & 231 vs 352 \\
$45 \sim 60$ & $346(111 \sim 1225)$ & $<60$ vs $\geq 60$ & 382 vs 317 & 0.574 \\
$\geq 60$ & $382(30 \sim 733)$ & $<45$ vs $\geq 60$ & 231 vs 382 & 0.742 \\
\hline
\end{tabular}

Table 7: Length of hospitalization and cost with or without distal irrigation

\begin{tabular}{|c|c|c|c|c|}
\hline $\begin{array}{c}\text { Patients receiving therapeutic } \\
\text { transverse colostomy }\end{array}$ & & $\begin{array}{c}\text { Distal } \\
\text { irrigation }\end{array}$ & $\begin{array}{l}\text { Without } \\
\text { irrigation }\end{array}$ & $p$-value \\
\hline \multirow{5}{*}{$\begin{array}{l}\text { With or without anastomotic } \\
\text { leakage }(n=19)\end{array}$} & Number of cases & 8 & 11 & \\
\hline & Hospitalization costs* & 9726 & 10829 & 0.516 \\
\hline & $\begin{array}{l}\text { Days of hospitalization after ostomy } \\
\text { (mean) }\end{array}$ & 10.0 & 8.0 & 0.585 \\
\hline & Median healing time (days) & 202 & 258 & \\
\hline & Mean healing time (days) & 207 & 429 & 0.150 \\
\hline \multirow{5}{*}{$\begin{array}{l}\text { RVF only, without anastomotic } \\
\text { leakage }(n=14)\end{array}$} & Number of cases & 5 & 9 & \\
\hline & Hospitalization costs $*$ & 10217 & 10058 & 0.934 \\
\hline & $\begin{array}{l}\text { Mean days of hospitalization after } \\
\text { ostomy }\end{array}$ & 5.4 & 8.4 & 0.268 \\
\hline & Median healing time (days) & 184 & 283 & \\
\hline & Mean healing time (days) & 184 & 462 & 0.384 \\
\hline
\end{tabular}

*USD, cost of stoma closure is not included. 
Table 8: Length of hospitalization and cost data

\begin{tabular}{lccc}
\hline & $\begin{array}{c}\text { RVF (+) } \\
\boldsymbol{n = 2 4}\end{array}$ & $\begin{array}{c}\text { RVF (-) } \\
\boldsymbol{n = 2 0 8 7}\end{array}$ & $\boldsymbol{p}$-value \\
\hline Days of hospitalization & 27.0 & 18.0 & 0.005 \\
Days of post-surgery hospitalization & 20.8 & 12.2 & 0.008 \\
Cost of hospitalization (USD) & 8115 & 5982 & 0.003 \\
\hline
\end{tabular}

Table 9: Previously reported RVF incidence rates

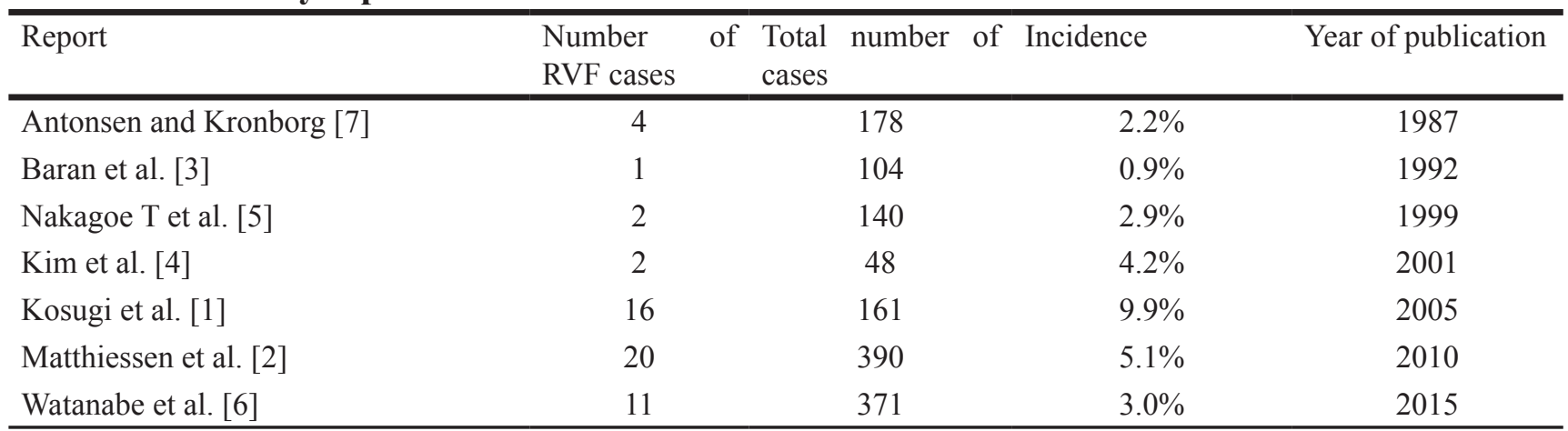

234 patients, Matthiessen et al. reported that prophylactic stoma can reduce the incidence of $\mathrm{AL}$, but its impact on RVF is unclear [27]. Theoretically, prophylactic stoma can reduce the incidence of RVF. However, ostomy itself has a negative impact on patients [28, 29]. Patients who undergo intraoperative prophylactic ostomy often present low tumor location, tissue adhesion, bowel edema, obstruction, and other risk factors. If intraoperative prophylactic ostomy is not performed, these patients may have higher RVF incidence and poorer prognosis. However, the prognosis of patients receiving prophylactic stoma is not comparable with that of patients who do not undergo prophylactic ostomy. In this study, we found no correlation between prophylactic ostomy and RVF occurrence. Therefore, the value of prophylactic ostomy for RVF remains controversial, and a prospective randomized controlled trial is warranted to further investigate this issue.

As RVF may be secondary to AL, it is not easy to form a drainage system. From our experience, we recommend puncture and other measures to open drainage in patients with $\mathrm{AL}$ and local abscess. Expansion of the rectal fistula can also facilitate drainage.

RVF occurrence significantly increases the duration and cost of hospitalization, with an average increase of 10 days in hospitalization, which does not include subsequent hospitalization for RVF treatments. This is similar to the increase of 7.3 days in the duration of hospitalization for gastrointestinal AL reported previously in the literature [30]. A previous study reported that gastrointestinal AL results in an additional cost of $\$ 24,129$ USD [30]. RVF occurrence has a serious impact on the quality of life of patients and increases their psychological burden. Many patients have long-term or even lifelong stoma bags, which can severely decrease their quality of life.
Our study suffered from some limitations. For example, this was a single-center retrospective study. Furthermore, we did not analyze the nutrition/malnutrition status of patients after LAR surgery. Moreover, the followup time for some patients was only six months. Despite these limitations, our study introduces novel analyses compared with previous publications [2, 6]. For example, our sample size was much larger than that of previous publications. In addition, our study is the first to address RVF after LAR among Chinese patients. Furthermore, we found that a short distance between the tumor and the anus, as well as unsatisfactory anastomosis, are a risk factors for RVF. Importantly, we didn't find any correlation between neoadjuvant chemoradiation and RVF. The incidence of RVF was $1.61 \%$. Lastly, we identified supplementary diverting stoma as a reasonable and effective treatment for post-LAR RVF. This information may help doctors to choose optimal treatment strategies for post-LAR RVF in clinical settings.

\section{MATERIALS AND METHODS}

\section{Patients}

A total of 5,200 patients with colorectal cancer who underwent LAR at Fudan University Shanghai Cancer Center between January 2006 and March 2016 were enrolled in this study. In 3,604 of these patients $(1,493$ women, average age $57.2 \pm 11.9$ years; range 22-93 years), the distance between the lower edge of the tumor and the anal verge was under $12 \mathrm{~cm}$. We performed detailed analyses on the 1,493 female patients. Laparotomy was performed on 1,322 patients and laparoscopic surgery on 171 patients. All patients 
received intraoperative circular-stapled anastomosis, with no patient receiving hand-sewn coloanal anastomoses. The date of last follow-up was September 30, 2016, and all patients were followed-up for at least six months. The recruiting process of our study is shown in (Figure 1).

\section{Criteria for diagnosis and evaluation of RVF healing}

RVF was diagnosed by clinical symptoms that indicate communication between the vagina and the rectum, such as feces, gas or intestinal fluid discharged from the vagina, and methylene blue solution flowing out of the vagina after it was injected into the patient's anus. RVF was confirmed by rectal and gynecological examination, and by endoscopic or radiological investigations.

The healing criteria for RVF are as follows: 1 . No feces or gas discharged from the vagina. 2. Confirmation by a surgeon that the RVF has been healed, after performing vaginal and rectal palpation; 3 . No methylene blue solution should flow out of the vagina after injecting it into the patient's anus and a applying pressure to the rectum,. 4. No RVF can be found through colonoscopy.

\section{Data analysis}

SPSS 22.0.0 software was used for data analysis. We performed univariate and multivariate logistic regression analyses to identify high-risk factors of RVF after LAR surgery. The variables used for univariate analysis were age, body mass index, hypertension, diabetes, history of weight loss, neoadjuvant radiotherapy, surgery duration, surgical method (laparoscopic surgery or laparotomy), methods of intraoperative prophylactic ostomy (transverse colostomy or ileostomy), unsatisfactory anastomosis (the definition including any of the following five criteria: poor blood supply for anastomosis site, obvious tension in anastomosis site, fragile tissue in anastomosis site, obvious edema in anastomosis site, and positive intraoperative air leak test), intraoperative blood loss, combined organ resection, distance between the lower edge of the tumor and the anal verge, maximal tumor diameter, $\mathrm{T}$ stage, days of hospitalization, days before surgery, and total hospitalization costs. Factors that showed statistical significance $(p<0.05)$ in univariate analysis were subjected to multivariate logistic regression analysis. $P$-values less than 0.05 were considered statistically significant.

\section{0 patients underwent anterior rectal resection}

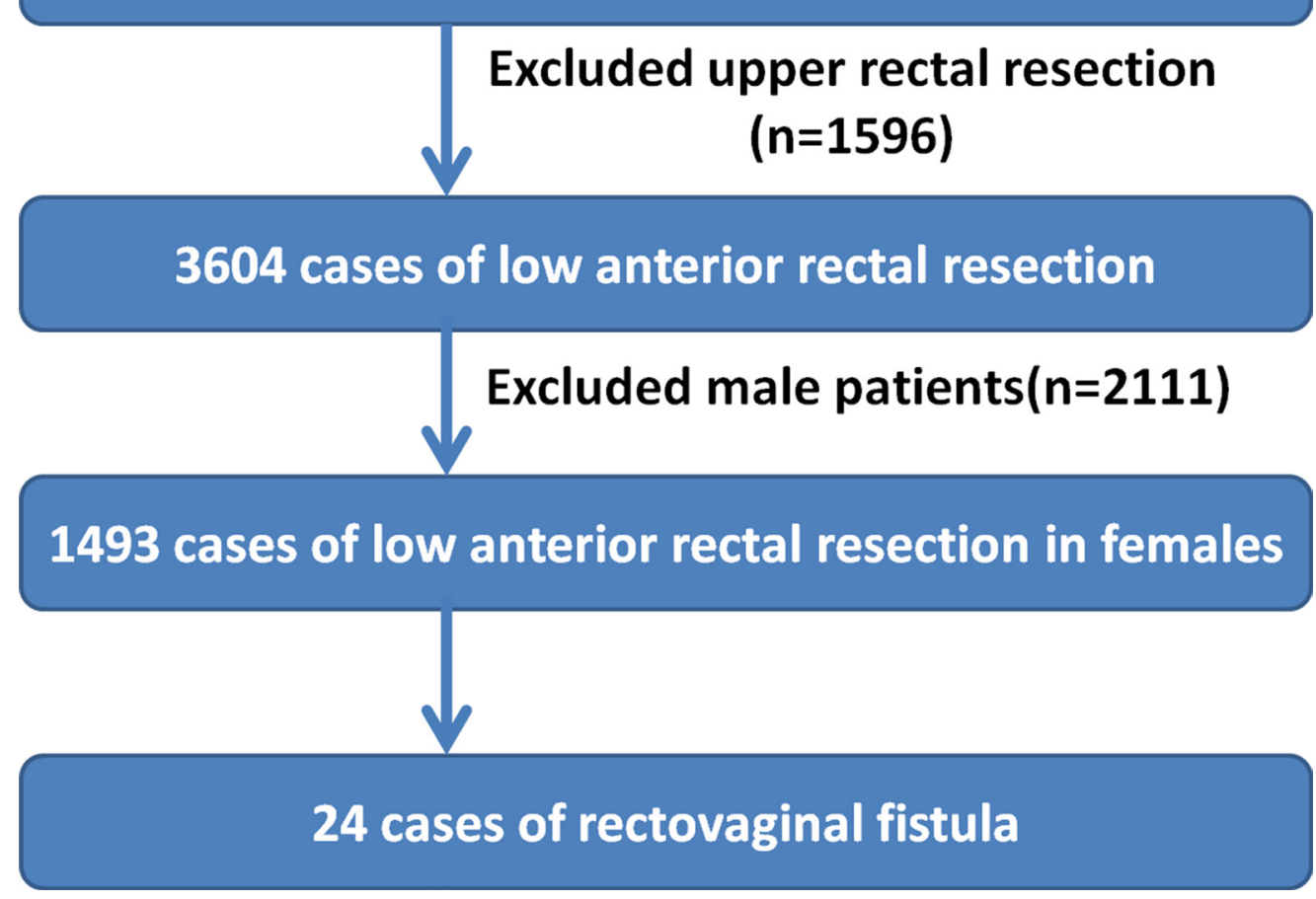

Figure 1: Work Flow Chart. Exclusions from 5200 patients who had a resection between January 2006 and March 2016. 


\section{Authors' contributions}

H.Z., T.G., Y.X and F.L conceived and designed the study. H.Z., T.G., Y.W., and C.L. acquired and analyzed the data. H.Z. and T.G. wrote the manuscript. Y.X, F.L. and S.C. revised the manuscript, and all authors read and approved of the final manuscript.

\section{Ethics statement}

This study was conducted according to the principles of the Declaration of Helsinki and was approved by the Research Ethics Committee of Fudan University Shanghai Cancer Center in China. All patients signed informed consent to participate in this study.

\section{CONFLICTS OF INTEREST}

None to declare.

\section{FUNDING}

This work was partially supported by the National Natural Science Foundation of China (grant no. 81472620), the Shanghai Science and Technology Planning Fund (grant no. 13140902100), the Shanghai Combination Study Project for Major Diseases (grant no. 2014ZYJB0101), the Fudan University Shanghai Cancer Center Fund (grant no. YJ201406), and the Shanghai Charity Cancer Fund (grant no. HYXH1608).

\section{REFERENCES}

1. Kosugi C, Saito N, Kimata Y, Ono M, Sugito M, Ito M, Sato K, Koda K, Miyazaki M. Rectovaginal fistulas after rectal cancer surgery: Incidence and operative repair by gluteal-fold flap repair. Surgery. 2005; 137:329-36. doi: 10.1016/j.surg.2004.10.004.

2. Matthiessen $\mathrm{P}$, Hansson $\mathrm{L}$, Sjödahl R, Rutegård $\mathrm{J}$. Anastomotic-vaginal fistula (AVF) after anterior resection of the rectum for cancer - occurrence and risk factors. Colorectal Dis. 2010; 12:351-7. doi: 10.1111/j.14631318.2009.01798.x.

3. Baran JJ, Goldstein SD, Resnik AM. The double-staple technique in colorectal anastomoses: a critical review. Am Surg. 1992; 58:270-2.

4. Kim NK, Lim DJ, Yun SH, Sohn SK, Min JS. Ultralow anterior resection and coloanal anastomosis for distal rectal cancer: functional and oncological results. Int J Colorectal Dis. 2001; 16:234-237.

5. Nakagoe T, Sawai T, Tuji T, Nanashima A, Yamaguchi H, Yasutake T, Ayabe Y. Successful transvaginal repair of a rectovaginal fistula developing after double-stapled anastomosis in low anterior resection: Report of four cases. Surg Today. 1999; 29:443-445. doi: 10.1007/BF02483037.
6. Watanabe J, Ota M, Kawaguchi D, Shima H, Kaida S, Osada S, Kamimukai N, Kamiya N, Ishibe A, Watanabe K, Matsuyama R, Akiyama H, Ichikawa Y, et al. Incidence and risk factors for rectovaginal fistula after low anterior resection for rectal cancer. Int J Colorectal Dis. 2015; 30:1659-1666. doi: 10.1007/s00384-015-2340-5.

7. Antonsen HK, Kronborg O. Early complications after low anterior resection for rectal cancer using the EEA TM, stapling device. Dis Colon Rectum. 1987; 30:579-583.

8. Taskesen F, Arikanoglu Z, Bostanci S, Oguz A, Uslukaya O, Turkoglu A, Veli Ulger B, Bac B. Rectovaginal fistulas: five years' experience. Clin Ter. 2014; 165:129-32. doi: 10.7417/CT.2014.1709.

9. Khanduja KS, Padmanabhan A, Kerner BA, Wise WE, Aguilar PS. Reconstruction of rectovaginal fistula with sphincter disruption by combining rectal mucosal advancement flap and anal sphincteroplasty. Dis Colon Rectum. 1999; 42:1432-7.

10. Göttgens KW, Smeets RR, Stassen LP, Beets G, Breukink SO. The disappointing quality of published studies on operative techniques for rectovaginal fistulas: a blueprint for a prospective multi-institutional study. Dis Colon Rectum. 2014; 57:888-98. doi: 10.1097/ DCR.0000000000000147.

11. Kaimakliotis P, Simillis C, Harbord M, Kontovounisios C, Rasheed S, Tekkis PP. A Systematic Review Assessing Medical Treatment for Rectovaginal and Enterovesical Fistulae in Crohn's Disease. J Clin Gastroenterol. 2016; 50:714-21. doi: 10.1097/MCG.0000000000000607.

12. Lo TS, Huang YH, Dass AK, Karim N, Uy-Patrimonio MC. Rectovaginal fistula: Twenty years of rectovaginal repair. J Obstet Gynaecol Res. 2016; 42:1361-1368. doi: 10.1111/ jog. 13066 .

13. Floodeen H, Hallböök $O$, Rutegård J, Sjödahl R, Matthiessen P. Early and late symptomatic anastomotic leakage following low anterior resection of the rectum for cancer: are they different entities? Colorectal Dis. 2013; 15:334-340. doi: 10.1111/j.1463-1318.2012.03195.x.

14. Fouda E, Nakeeb A, Magdy A, Hammad EA, Othman G, Farid M. Early detection of anastomotic leakage after elective low anterior resection. J Gastrointest Surg. 2011; 15:137-44. doi: 10.1007/s11605-010-1364-y.

15. Maeda H, Okamoto K, Namikawa T, Akimori T, Kamioka N, Shiga M, Dabanaka K, Hanazaki K, Kobayashi M. Rarity of late anastomotic leakage after low anterior resection of the rectum. Int J Colorectal Dis. 2015; 30:831-834. doi: 10.1007/s00384-015-2207-9.

16. Boccola MA, Buettner PG, Rozen WM, Siu SK, Stevenson AR, Stitz R, Ho YH. Risk Factors and Outcomes for Anastomotic Leakage in Colorectal Surgery: A SingleInstitution Analysis of 1576 Patients. World J Surg. 2011; 35:186-95. doi: 10.1007/s00268-010-0831-7.

17. McDermott FD, Heeney A, Kelly ME, Steele RJ, Carlson GL, Winter DC. Systematic review of preoperative, 
intraoperative and postoperative risk factors for colorectal anastomotic leaks. Br J Surg. 2015; 102:462-79. doi: 10.1002/bjs. 9697 .

18. Wu Z, van de Haar RC, Sparreboom CL, Boersema GS, Li Z, Ji J, Jeekel J, Lange JF. Is the intraoperative air leak test effective in the prevention of colorectal anastomotic leakage? A systematic review and metaanalysis. Int $\mathrm{J}$ Colorectal Dis. 2016; 31:1409-17. doi: 10.1007/s00384-016-2616-4.

19. Kwon S, Morris A, Billingham R, Frankhouse J, Horvath K, Johnson M, McNevin S, Simons A, Symons R, Steele S, Thirlby R, Whiteford M, Flum DR, et al. Routine Leak Testing in Colorectal Surgery in the Surgical Care and Outcomes Assessment Program. Arch Surg. 2012; 147:345-51. doi: 10.1001/archsurg.2012.12.

20. Champagne BJ, Mcgee MF. Rectovaginal fistula. Surg Clin North Am. 2010; 90:69-82. doi: 10.1016/j.suc.2009.09.003.

21. Sebag-Montefiore D, Stephens RJ, Steele R, Monson J, Grieve R, Khanna S, Quirke P, Couture J, de Metz C, Myint AS, Bessell E, Griffiths G, Thompson LC, et al. Preoperative radiotherapy versus selective postoperative chemoradiotherapy in patients with rectal cancer (MRC CR07 and NCIC-CTG C016): a multicentre, randomised trial. Lancet. 2009; 373:811-20. doi: 10.1016/S01406736(09)60484-0.

22. Corte H, Maggiori L, Treton X, Lefevre JH, Ferron M, Panis Y. Rectovaginal Fistula: What Is the Optimal Strategy?: An Analysis of 79 Patients Undergoing 286 Procedures. Ann Surg. 2015; 262:855-60. doi: 10.1097/ SLA.0000000000001461.

23. Das B, Snyder M. Rectovaginal Fistulae. Clin Colon Rectal Surg. 2016; 29:50-6. doi: 10.1055/s-0035-1570393.
24. Huang S, Chi P, Lin H, Lu X, Huang Y, Jiang W, Xu Z, Sun Y, Ye D, Wang X. [Risk factors and clinical features of delayed anastomotic fistula following sphincter-preserving surgery for rectal cancer]. [Article in Chinese]. Zhonghua Wei Chang Wai Ke Za Zhi. 2016; 19:390-5.

25. Lamazza A, Fiori E, Sterpetti AV, Schillaci A, De Cesare A, Lezoche E. Endoscopic placement of self-expandable metallic stents for rectovaginal fistula after colorectal resection: a comparison with proximal diverting ileostomy alone. Surg Endosc. 2016; 30:797-801. doi: 10.1007/ s00464-015-4246-2.

26. Valente MA, Hull TL. Contemporary surgical management of rectovaginal fistula in Crohn's disease. World J Gastrointest Pathophysiol. 2014; 5:487-495. doi: 10.4291/ wjgp.v5.i4.487.

27. Veenhof AA, van der Peet DL, Meijerink WJ, Cuesta MA. Defunctioning stoma reduces symptomatic anastomotic leakage after low anterior resection of the rectum for cancer: a randomized multicenter trial. Ann Surg. 2008; 247:719-20. doi: 10.1097/SLA.0b013e31816a7493.

28. Lambertz A, Lüken B, Ulmer TF, Böhm G, Neumann UP, Klink CD, Krones CJ. Influence of diversion stoma on surgical outcome and recurrence rates in patients with rectovaginal fistula - A retrospective cohort study. Int J Surg. 2015; 25:114-7. doi: 10.1016/j.ijsu.2015.12.005.

29. Ommer A, Herold A, Berg E, Fürst A, Schiedeck T, Sailer M. German S3- Guideline: rectovaginal fistula. Ger Med Sci. 2012; 10:Doc15. doi: 10.3205/000166.

30. Hammond J, Lim S, Wan Y, Gao X, Patkar A. The burden of gastrointestinal anastomotic leaks: an evaluation of clinical and economic outcomes. J Gastrointest Surg. 2014; 18:1176-1185. doi: 10.1007/s11605-014-2506-4. 